\title{
Literasi Tubuh Virtual dalam Aplikasi Teknologi Augmented Reality PASUA PA
}

\author{
Sri Rustiyanti ${ }^{1}$, Wanda Listiani ${ }^{2}$, Fani Dila Sari ${ }^{3}$, Ida Bagus Gede Surya Peradantha ${ }^{4}$ \\ Program Studi Antropologi Budaya, Fakultas Budaya dan Media \\ Institut Seni Budaya Indonesia (ISBI) Bandung \\ Jl. Buahbatu No 212 Bandung 40265 \\ Tlp. 081221418454, E-mail: rustiyantisri@yahoo.com
}

\begin{abstract}
Body language is a gesture that has meaning to express the expression of a dancer. The dancer's body literacy is an empirical experience possessed in the ability to read choreography and do it continuously so that choreography becomes a body language literacy that is trained to become corporal acrobatic, corporal impulses, corporal instinc, and virtuosity as aesthetic experiences. This research reads and writes choreography of three dances namely Karwar Dance (Papua), Cikeruhan Dance (Sunda), and Guel Dance (Aceh) from dancer's body language literacy to transform technology literacy by using augmented reality application media, combining reality and virtual in a form show. This study uses qualitative methods that focus more on the case study by involving problems and the purpose of viewing the performing arts from the visual culture of technology literacy. This paper is the result of a research by a consortium of Kemenristekdikti to redefine the identity of the dancer's body, including a body shaped, well-controlled and well-established, patterned, there are standard movements and complete, occupying space well by applying and utilizing technology to produce findings from this research, namely AR Pasua PA (Augmented Reality Papua-Sunda-Aceh Performent Art). This finding is a new formula for the performance by utilizing the transfer from body language literacy to technology literacy.
\end{abstract}

Keywords: body language literacy, technology literacy, augmented reality, digital art, AR Pasua PA.

\begin{abstract}
ABSTRAK
Bahasa tubuh adalah gesture yang mempunyai makna untuk mengungkapkan ekspresi dari seorang penari. Literasi tubuh penari merupakan pengalaman empirik yang dimiliki dalam kemampuan membaca koreografi dan melakukannya secara terus menerus sehingga koreografi yang dilakukan menjadi sebuah literasi bahasa tubuh yang terlatih menjadi corporal acrobatic, corporal impulses, corporal instinc, dan virtuisitas sebagai pengalaman estetis. Penelitian ini menganalisa koreografi tiga tarian yaitu Tari Karwar (Papua), Tari Cikeruhan (Sunda), dan Tari Guel (Aceh) dari literasi bahasa tubuh penari untuk ditransformasikan melalui teknologi Augmented Reality dengan menggabungkan realitas dan virtual dalam bentuk pertunjukan. Metode penelitian yang digunakan adalah kualitatif dengan memfokuskan diri pada seni pertunjukan, budaya visual dan literasi teknologi. Penelitian ini merupakan hasil penelitian konsorsium seni KRUPT ristekBRIN. Penelitian yang meredefinisikan kembali identitas tubuh penari, antara lain tubuh berbentuk, dikuasai dengan baik dan mapan, berpola, sesuai dengan standar gerak yang pakem dan selesai, menempati ruang dengan baik dan mengaplikasi dan memanfaatkan teknologi sehingga capaian literasi tubuh dengan penggunaan teknologi digital 4.0 dalam bentuk aplikasi AR PASUA PA. Hasil penelitian ini merupakan formula baru seni pertunjukan dengan memanfaatkan alih wahana dari literasi tubuh ke dalam teknologi virtual.
\end{abstract}

Kata kunci: literasi bahasa tubuh, literasi teknologi, augmented reality, seni digital, AR Pasua $P A$. 


\section{PENDAHULUAN}

Tulisan ini sebagai publikasi dari hasil Penelitian Konsorsium Bidang Seni Pertunjukan yang merupakan perpaduan Penelitian Seni dan Seni Pertunjukan melalui media augmented reality. Penelitian Konsorsium bidang Seni ini mengangkat tiga fenomena budaya yang ada di Nusantara yaitu Papua, Sunda, dan Aceh. Struktur dari ketiga wilayah territorial ini menjadi sebuah nama realitas virtual yang khas berupa Augmented Reality (AR) PASUA (Papua-Sunda-Aceh) Performance Arts (PA). Pemahaman tentang Augmented Reality (AR) mengkombinasikan kemampuan manusia (suara, peraba dll) dengan menggunakan objek virtual untuk memfasilitasi interaksi dunia-nyata dan persepsi otentik pengguna. Pertunjukan karya seni ini memang tidak bisa dikatakan sebagai suatu kesatuan yang biasa tapi justru layak diapresiasi dengan kedinamisannya. Visualisasi virtual pertunjukan augmented reality merupakan bentuk seni baru, yang memang ini bertujuan untuk membuat penikmatnya merasa seolah berada di tengah suatu ilusi akan realita yang digambarkan melalui sebuah alat interaktif antara virtual dan realita. Penggabungan antara virtual dan realita ini merupakan sebuah kreativitas yang dibangun untuk perubahan.

Dalam perkembangan pada zaman peradaban masyarakat modern, pemahaman literasi yang pada awalnya merupakan kemampuan seseorang dalam menerima, memahami, dan mengolah informasi saat proses membaca dan menulis. Sejalan dengan perkembangan peradaban pemahaman literasi menjadi lebih luas, tidak hanya sekedar dalam membaca dan menulis saja. Literasi dipahami lebih luas, baik dari bahasa hingga menyangkut fenomena kultural maupun yang berkaitan dengan permasalahan praktik sosial dan politik. Pemahaman baru dari literasi tubuh virtual menunjukkan paradigma baru dalam upaya memaknai literasi, seni pertunjukan dan pembelajarannya. Banyak pemahaman literasi yang muncul karena perkembangan sains, konsep, ideologi, bahkan teknologi modern yang mengakibatkan mucul pemahaman berbagai jenis literasi, seperti literasi media, literasi komputer, literasi sains, literasi budaya, litarasi tubuh, literasi akal, literasi rasa, literasi bahasa, literasi sekolah, dan sebagainya.

Literasi sebagai proses, tidak terwujud secara serta merta, tetapi secara kritis melalui tahapan-tahapan proses yang dilakukan yaitu mengapresiasi, memahami, menghayati, menganalisis, mengaplikasi, dan mentransformasi teks. Kesemuanya merujuk pada kompetensi atau kemampuan yang lebih dari sekedar kemampuan membaca dan menulis. Literasi didefinisikan sebagai kemampuan membaca dan menulis. Menurut Alberta, literasi merupakan kemampuan membaca dan menulis, menambah pengetahuan dan ketrampilan, berpikir kritis dalam memecahkan masalah, serta kemampuan berkomunikasi secara efektif yang dapat mengembangkan potensi dan berpartisipasi dalam kehidupan masyarakat. Berpijak pada pendapat Alberta mendefinisikan literasi sebagai "kemampuan individu untuk membaca, menulis, berbicara, 
menghitung, dan memecahkan masalah pada tingkat keahlian yang diperlukan dalam pekerjaan, keluarga, dan masyarakat" (Elizabeth Sulzby, 1986; Harvey J. Graff, 2006; Jack Goody; Merriam - Webster; UNESCO). Definisi ini memaknai literasi dari perspektif yang lebih kontekstual.

Daridefinisiiniterkandungmaknabahwa definisi literasi tergantung pada keterampilan yang dibutuhkan dalam lingkungan tertentu. Literasi lebih dari sekedar kemampuan baca tulis. Namun lebih dari itu, literasi adalah kemampuan individu untuk menggunakan segenap potensi dan skill yang dimiliki dalam hidupnya. Dengan pemahaman bahwa literasi mencakup kemampuan membaca kata bahkan dapat membaca dunia. Meminjam istilah hiperrealitas, bahwa kita dapat menangkap fenomena realita lebih konkrit lagi dengan adanya teknologi dan berbagai media yang dapat digunakan untuk membaca fenomena (Piliang, 1998: 37). Dengan demikian, pada zaman masyarakat modern ini, manusia dalam melakukan berbagai aktivitas dan kreativitas dalam waktu yang singkat bahkan bersamaan berbagai kegiatan dapat dilakukan secara serentak. Istilah ini dinamakan dromologi, yang merupakan pemadatan ruang dan waktu (Piliang ,2018: 55).

Di Indonesia, tarian tradisi berhubungan erat dengan unsur-unsur, seperti: agama, kepercayaan, dan unsur magis, yang sudah berkembang sejak zaman primitif. Tari merupakan refleksi nyata dari sejarah Folklor Indonesia yang sudah mengalami perjalanan waktu sejarahyang cukup panjang (Supriyanto, 2018: 45). Literasi bahasa tubuh dari gerak tari diartikan sebagai laku olah gerak dan rasa, yang dikenal dengan sebutan duduak bapamenan tagak baparentang atau kaulinan sebagai permainan yang memiliki akar gerak ilmu bela diri pencak (Rustiyanti, 2011: 296; Sedyawati, 1999: 72; Murgiyanto, 1991: 276; Maryono, 1998: 9; dan Nor, 1986: 26). Adapun motif-motif gerak dalam Tari Karwar (Papua), seperti: mas kopra, mas fyer, mun marmar, inanai, man prupe, kref, in gaimun, dan mansibin; Tari Cikeruhan (Sunda), seperti rogok, depok, giles, peupeuh, meprek keupeul, nyabet, pasang, tangkis, kuntulan galieur, gileuk katuhu, gileuk kenca, tugelan, gitek kenca, gitek katuhu, candet, galieur, golong, kepret soder, tincak tilu, balungbang, gitek suway, keupat tilu, jujungkungan, muter, keupat ngalageday, dan sebagainya; sedangkan Tari Guel (Aceh) seperti salam semah, kepur nunguk, sining lintah, sengker kalang, munatap, cincang nangka. Ketiga tari tersebut mencakup gerak tari, gerak pencak, dan gerak silat yang memiliki unsur-unsur dan ciri-ciri umum antara lain: (1) ekspresi penari secara artistik, (2) gerak yang dilakukan oleh manusia, (3) gerak yang berpola dan berbentuk, (4) gerak stilasi, (5) mengandung ritme, (6) di dalam ruang, (7) mempunyai simbol atau arti, dan (8) menyampaikan pesan. Seringkali pengertian ini tidak terlepas adanya unsur cerita, dialog, nyanyian, akrobatik dan demonstrasi kekebalan (Sedyawati, 1999: 69; dan Kapita Selekta, 1984: 111).

Penari dalam kebebasan berekspresi, eksplorasi, dan improvisasi dengan melalui beberapa tahap seperti mendengarkan, mengalami, dan melakukan bahasa tubuh gerak tari yang berulang-ulang yang kemudian 
menjadi gerak milik sendiri (Rustiyanti dan Listiani, 2017: 221). Elemen-elemen koreografinya yaitu tubuh, ruang, waktu, dan tenaga. Penggunaan sumber gerak dalam pencak silat dengan penekanan aspek bentuk dasarnya pada sikap dan unsur gerak kaki, sedangkan aspek dinamik dan kualitas gerak mengalami perubahan sesuai dengan tujuan. Sebuah gerak pencak dapat menjadi lebih keras, tajam, dan cepat apabila digunakan dalam bersilat, sebaliknya menjadi lemah dan tidak terlalu tajam apabila dipakai dalam tari.

Menurut Holt, ciri khusus tarian Indonesia adalah terikat dengan tanah dan tidak menjauhinya. Posisinya duduk, berlutut, membungkuk ataupun setengah bungkuk (LIPI, 1984: 117). Hal ini juga banyak terlihat pada pemilihan gerak yang dilakukan para penari Karwar Papua), Cikeruhan (Sunda), dan Guel (Aceh). Dari beberapa karyanya pada adegan tertentu, tanpa disadari ataupun disadari dengan kreatif, ada beberapa ciri gerak yang memberikan kesan sekilas tetapi membekas dalam pengamatan terhadap gerak tersebut, seperti loncatan tinggi dengan kaki membuka lebar kemudian jatuh ke bawah dengan tempo cepat dan langsung berdiri, badan melayang dengan lembut dalam tempo cepat rebah ke bawah, angkat kaki yang ringan walau posisi kaki rengkuh (disebut juga kuda-kuda). Oleh karena itu ciri-ciri tarian tadisi penggunaan istilah rengkuh/pitunggue/ mendhak, karena gerak kakinya ditikberatkan pada bagian bawah, baik putaran badan dengan kaki sebagai sumbu (poros), putaran badan yang hanya diikuti bahu dan kepala dengan gerak sentak yang mengejutkan, maupun gerak vibrasi kaki yang cepat, padat, dan kuat (Rustiyanti, 2019: 170).

Monroe Beardsley mengatakan metafora adalah 'sebuah puisi miniatur' (1958: 134). Dengan demikian hubungan antara makna literal dan makna figuratif dalam sebuah metafora adalah seperti sebuah versi penjembatan dalam sebuah kalimat tunggal dari harmonisasi signifikansi kompleks yang memberikan karakter pada karya literer sebagai sebuah keutuhan (sedya). Istilah literer di sini maksudnya adalah sebuah karya wacana yang berbeda dari setiap karya wacana lain, khususnya wacana sains, di mana mempunyai makna eksplisit dan implisit ke dalam suatu hubungan. Analisis interpretasi gerak untuk mengetahui lebih jelas, penulis sajikan beberapa ragam gerak dasar dalam Tari Minang yang bersumber dari pencak silat (Murgiyanto, 1991: 274) atau dengan kata lain mempunyai kemampuan untuk 'bermain' dengan elemen-elemen yang familiar dan menatanya secara tidak familiar dengan menarik, yang cukup memberikan sumber inspirasi dalam bereksplorasi (Murgiyanto, 2002: 61). Hal ini menjadi sebuah konsep kebudayaan yang berasal dari filsafat, estetika kritis, kritik kesusatraan, sejarah, antropologi, dan sosiologi. Kebudayaan sebagai sebuah konsep harus dipandang dalam tradisi-tradisi, konteks idealisme, dan materialisme, bukan sebagai invensi modern (Jenks, 2017: v).

\section{METODE}

Penelitin ini menggunakan pendekatan kualitatif dengan model kajian ilmu budaya. 
Tahapan mengenal, memahami, menjelaskan atau menganalisis suatu fenomena budaya berdasarkan sebuah alur pikir teori budaya yang relevan. Relevan atau berhubungan dengan teori tertentu yang dapat menjelaskan peristiwa budaya literasi tubuh virtual dalam teknologi 4.0 terjadi. Dengan kata lain antara penelitian kajian budaya, teknologi 4.0 dan teori seni pertunjukan virtual tidak bisa dipisahkan. Penelitian ini menganalisis literasi tubuh dalam teknologi Augmented Reality PASUA PA.

Fenomena seni pertunjukan di era revolusi industri menempatkan tubuh penari sebagai teks yang dapat diinterpretasikan. Kebudayaan dapat diartikan sebagai keseluruhan simbol, pemaknaan, penggambaran (image), struktur aturan, kebiasaan, nilai, pemrosesan informasi, dan pengalihan pola-pola konvensi pikiran, perkataan dan perbuatan/tindakan yang dibagikan di antara para anggota suatu sistem sosial dan kelompok sosial dalam suatu masyarakat (Liliweri, 2011: 4). Ketubuhan penari sebagai budaya sekaligus teks menerangkan bahwa 'keseluruhan', seluruh arti dan makna simbol dapat dibedakan, namun arti dan makna simbol-simbol itu tidak dapat dipisahkan. Manusia dapat membedakan arti dan makna simbol melalui kebudayaan tubuh virtual.

\section{HASIL DAN PEMBAHASAN}

Perkembangan teknologi digital begitu cepat tentunya akan terus menarik untuk dikaji sebagai bahan penelitian dan penciptaan seni. Kemajuan ini adalah salah satu hal yang mendorong seniman banyak menciptakan karya-karya seni bernuansa elektronik dan juga membuat jaringan kerja seni virtual. Teknologi telah berkembang sedemikian pesat, baik sebagai sebagai penunjang terciptanya gagasan bentuk (aspek intrinsik) maupun juga gagasan pengusung isi (aspek ekstrinsik), yang juga menampilkan fleksibilitas dalam mengusung proses kolaborasi antar berbagai disiplin ranah seni. Materi pertunjukan sebagai karya seni merupakan proses kreativitas yang dihasilkan oleh seniman yang diungkapkan melalui berbagai medium, baik secara visual, audio, maupun audiovisual. Seniman sebagai koreografer adalah pihak yang mengelola materi-materi, serta mengkoordinasi segala sesuatu yang berkaitan dengan materi sajian suatu pertunjukan.

Kesenian tradisi yang ada di Papua (Tari Karwar), Sunda (Tari Cikeruhan), dan Aceh (Tari Guel) melalui proses konservasi, rekonstruksi, modifikasi, dan inovasi dengan memanfaatkan teknologi Augmented reality menjadi sebuah literasi teknologi AR PASUA PA (Augmented Reality Papua-Sunda-Aceh Performing Art). Literasi teknologi dalam seni pertunjukan tradisi dan kreasi ini bertujuan: 1) Mengembangkan media pembelajaran dan pengetahuan mahasiswa akademik (khususnya ISBI Tanah Papua, ISBI Bandung, dan ISBI Aceh; serta pada umumnya PT Seni yang ada di Indonesia, seperti: ISI Denpasar, ISI Jogyakarta, ISI Surakarta, ISI Padangpanjang, STKW Surabaya, dan IKJ) dengan aplikasi Teknologi AR; 2) Membantu tingkat pemahaman mahasiswa terkait literasi 
seni digital yang berbasis seni tradisi dalam proses pembelajaran seni pertunjukan; 3) Meningkatkan kemampuan mahasiswa dalam berpikir secara kritis dan aplikatif khususnya penggunaan teknologi AR PASUA PA; 4) Melalui seni teknologi AR PASUA PA, dapat menumbuhkan dan mengembangkan 'rasa', 'karakter' serta 'identitas' melalui literasi bahasa tubuh penari yang merupakan subtansi yang tidak dapat ditinggalkan, meskipun sudah ada teknologi canggih; 5) Menggali nilai lokal dalam aplikasi AR PASUA PA, pencarian data yang terkumpul dari para narasumber sebagai manifact yang sangat penting; 6) Mengembangkan AR PASUA PA sebagai alternatif literasi teknologi dalam seni pertunjukan di tengah-tengah masyarakat secara luas; dan 7) Seni teknologi AR PASUA PA dapat membantu meningkatkan kualitas dan media pembelajaran mahasiswa.

Literasi teknologi 4.0 menjadi salah satu media alternatif seni pertunjukan yang memiliki waktu real-time. Augmented Reality (AR) memberikan informasi sensoris langsung pada penonton pertunjukan melalui pengalaman mereka dalam mengapresiasi seni pertunjukan. Augmentasi visual pada penonton memiliki potensi meningkatkan produktivitas dan kemampuan antara lain: Pertama, meningkatkan kemampuan praktis dan interpretasi bermakna seni pertunjukan. Kedua, penonton dapat melakukan kolaborasi langsung dengan objek seni pertunjukan yang dilihatnya melalui tools AR. Literasi bahasa tubuh dari gerak tari sebagai kegiatan hubungan keterlibatannya antara penonton dan literasi teknologi dalam bingkai kegiatan pertunjukan literasi bahasa tubuh, seperti yang dijelaskan oleh Nick bahwasannya seni pertunjukan merupakan hubungan antara penonton dan objek pertunjukannya (1994: 37). Literasi teknologi AR dalam pertunjukan merupakan representasi pertunjukan yang tidak konvensional, hasil eksperimen baik dalam seni tari, lukisan, patung maupun drama (Nick, 1994: 3). Visualisasi literasi bahasa tubuh dengan dukungan literasi teknologi AR memiliki potensi media pendidikan karakter bagi penonton di zaman peradaban masyarakat modern ini. Tren revolusi industri 4.0 meningkatkan penggunaan data real time dengan 3D scanning dan umpan balik melalui AR. Scanning 3D merujuk pada kedalaman bentuk dan gerak literasi bahasa tubuh dengan representasi 3D dalam ruang. Scanning dalam eksperimentasi oleh teknologi sensor Microsoft Xbox Kinect (TM) misalnya menggunakan kombinasi optis dan kedalaman kamera (Peake, 2017: 2).

Aplikasi ARPASUAPAinimengapresiasi kesenian 3 daerah (Papua, Sunda, dan Aceh) secara sekaligus dalam waktu dan ruang yang sama sehingga menjadi lebih efektif dan effisien. Berikut proses pembuatan AR PASUA PA di Papua, Sunda dan Aceh.

Teknologi AR PASUA PA memberikan manfaat literasi digital pada mahasiswa dan masyarakat seni untuk menambah perbendaharaan visual gerak tari, literasi tubuh penari dan kosa kata seni pertunjukan. Mahasiswa dapat mengoptimalkan kinerja aktif, mendapat berbagai wawasan dan informasi, kemampuan interpersonal, kemampuan verbal, kemampuan analisis dan 

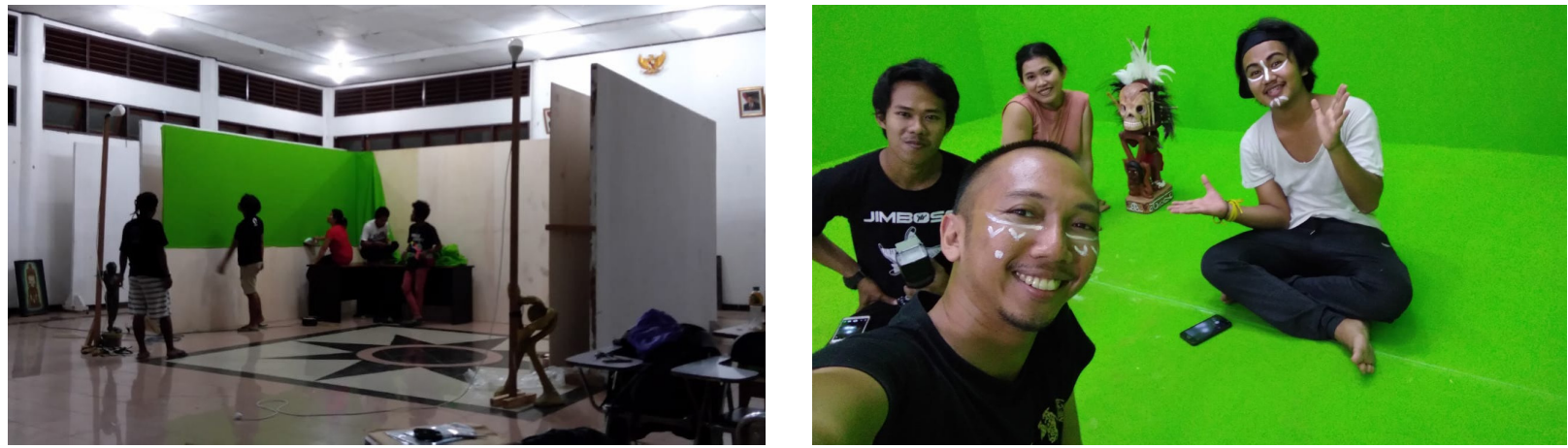

Gambar 1. Proses pembuatan green screen tim produksi Tari Karwar (Papua) Sumber : Tim Peneliti Konsorsium, 2019
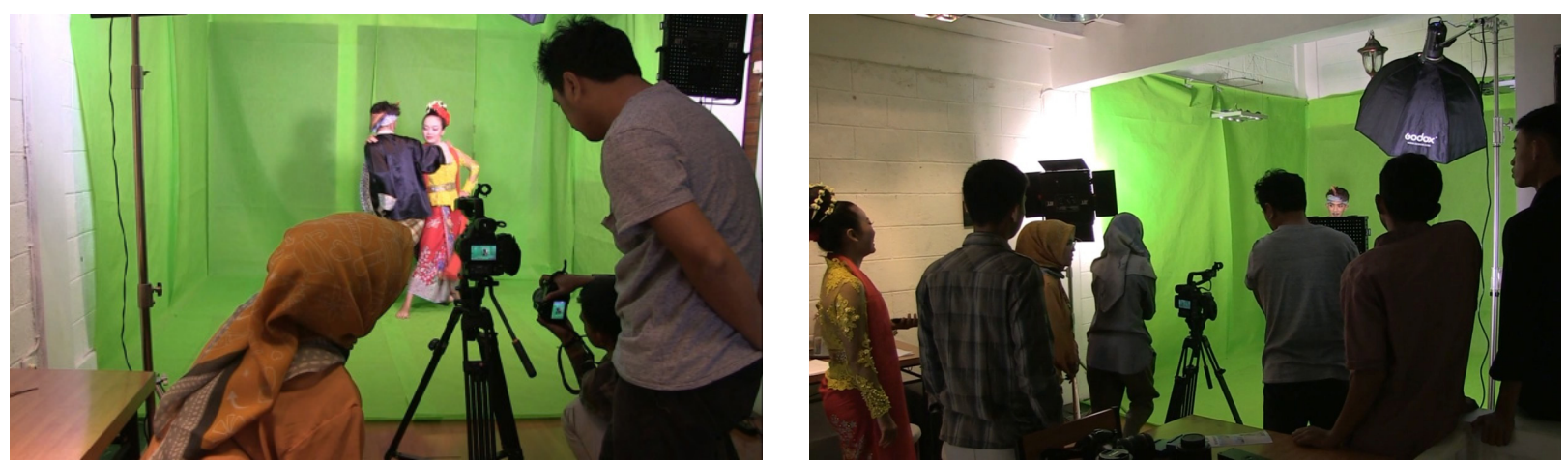

Gambar 2. Proses pembuatan green screen tim produksi Tari Cikeruhan (Sunda) Sumber : Tim Peneliti Konsorsium, 2019
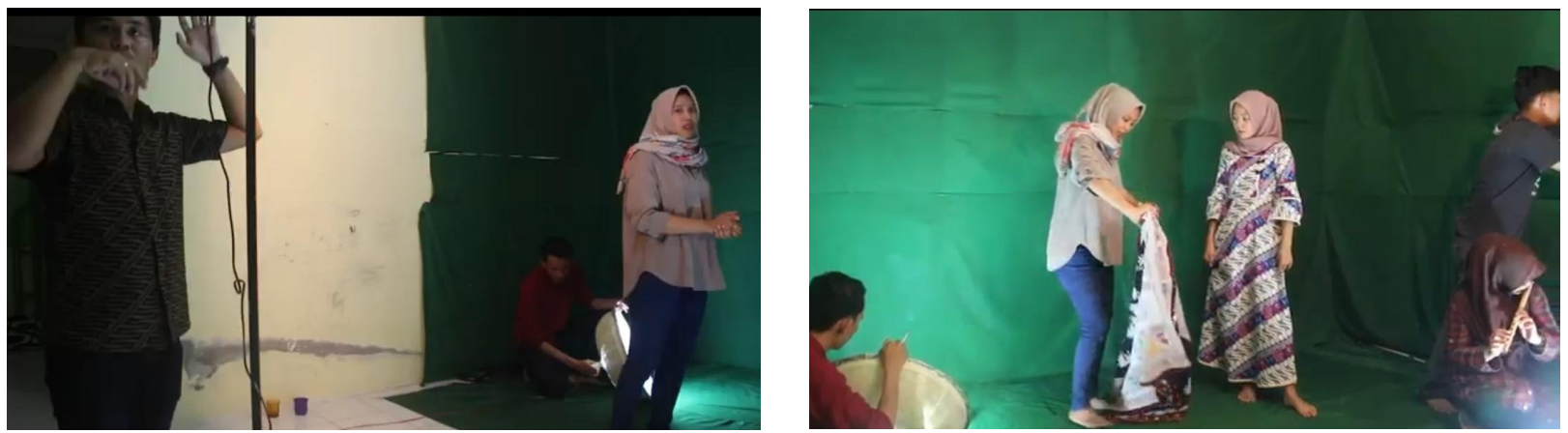

Gambar 3. Proses pembuatan green screen tim produksi Tari Gual (Aceh) Sumber : Tim Peneliti Konsorsium, 2019

berpikir, membantu meningkatkan daya fokus dan kemampuan konsentrasi.

Mengikuti perkembangan kreativitas seni digital saat ini, seringkali menggunakan dengan istilah 'media baru'. Istilah ini mempertegaskan kehadiran karya seni seperti instalasi, video art, web art, digital art, dan sebagainya yang bercirikan dan mempunyai nuansa pengaruh peralatan baru masa kini, misalnya: komputer, kamera digital, video, perangkat internet. Dari sekian banyak kemajuan teknologi yang ada, mungkin elektroniklah yang paling menonjol dan terbanyak menguasai serta digunakan dalam kehidupan masyarakat terutama di kotakota besar. Kemajuan teknologi berupa peralatan elektronik ini memudahkan untuk berkreativitas dapat dipahami dalam konteks 
ranah yang tidak hanya terbatas pada ranah industri atau ekonomi, tetapi meliputi ranah sosial, politik, kebudayaan, dan keagamaan.

Proses penciptaan suatu karya tidak dapat terlepas dari ide kekaryaan, referensi karya, dan bentuk karya itu sendiri. Tahapan dalam proses produksi suatu karya seni dengan melewati dimensi: 1) gagasan penciptaan; 2) sumber penciptaan; dan 3) bentuk penciptaan (Wiradiredja, 2015, hlm. 65). Proses kreatif literasi teknologi AR PASUA PA meliputi berbagai upaya dari rekonstruksi seni tradisi tari Karwar di Papua. Literasi dasar dalam bentuk kemampuan membawakan ragamragam gerak seperti jongkok, loncat, lompat, lari, jalan, putar, jinjit, dan sebagainya untuk mengoptimalkan kemampuan seseorang dalam bergerak dalam keseharian, bergerak dalam berkesenian, dan bergerak dalam bekerja. Literasi dasar ini sebagai material dan konten dari literasi teknologi AR PASUA $P A$. Selanjutnya kemampuan literasi referensi sebagai kemampuan dalam memahami dan membedakan ragam-ragam gerak yang ada dalam Tari Karwar (Papua), Tari Cikeruhan (Sunda), dan Tari Guel (Aceh), membandingkan secara komprehensif, mencari perbedaan dan persamaan karakteristik ketiga bentuk tarian tersebut, sehingga mendapatkan informasi lengkap baik secara tekstual maupun kontekstual.

Penggunaan literasi dasar dan literasi referensi ketiga bentuk tarian dan melakukan tahap alih wahana literasi media yang merupakan kemampuan untuk mentransformasikan literasi bahasa tubuh ke literasi digital AR PASUA PA. Proses literasi

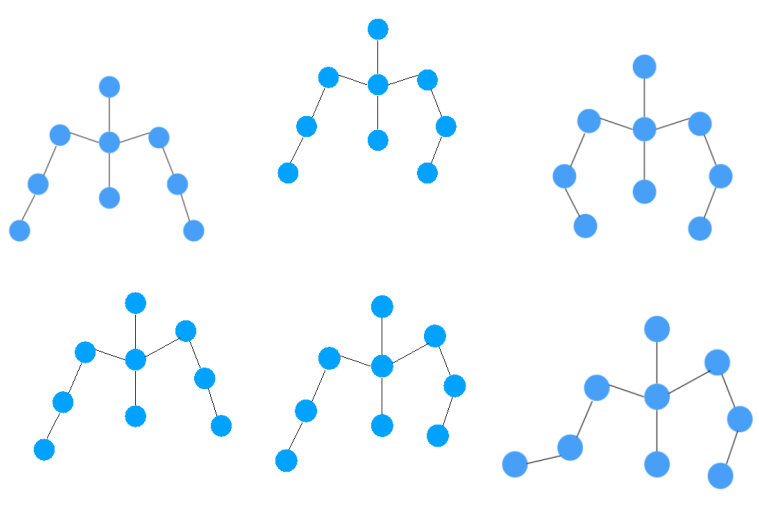

Gambar 4. Literasi Tubuh Virtual Sumber : Tim Peneliti Konsorsium, 2020

digital AR PASUA PA dengan menggunakan media Augmented Reality menggabungkan realitas dan virtual. Tahap literasi digital AR PASUA PA merupakan kemampuan dalam mengetahui dan memahami halhal yang berhubungan dengan teknologi misalnya hardware dan software, mengerti cara menggunakan internet serta memahami etika dalam menggunakan teknologi, dan sebagainya. Selanjutnya dari tahapan-tahapan literasi tersebut terbentuk sebuah literasi visual sebagai pemahaman yang lebih mendalam dengan kemampuan menginterpretasi dan memberi makna dari AR PASUA PA yang berbentuk gambar atau visual. Literasi visual hadir dari pemikiran bahwa suatu gambar bisa "dibaca" dan artinya bisa dikomunikasikan dari proses apresiasi.

Literasi bahasa tubuh tari tradisi (Tari Karwar, Tari Cikeruhan, dan Tari Guel) pada umumnya 'menapak ke bumi'. Artinya, konsep tarian itu dipola untuk ditarikan dengan tancapan kaki kuda-kuda yang kuat dan lutut merendah. Jarang sekali ditemukan angkatan kaki secara berlama-lama dan jika gerakan itu diulang, pengulangan tidak dalam intensitas yang tinggi. Kalaupun ada, gerakan 
mengangkat kaki itu (kiri atau kanan), biasanya hanya terjadi dalam hitungan detik. Jika kaki itu diangkat, penari selalu dengan segera menginjakkan kakinya kembali ke 'bumi'. Misalnya pada gerakan angkatan kaki sabetan dalam tari Jawa atau jangkung ilo dalam tari Sunda. Tancapan kaki, atau dalam istilah geraknya disebut adeg-adeg atau kuda-kuda, dalam Pencak Silat, justru dijadikan salah satu ukuran baik-tidaknya kriteria seorang penari. Fenomena ini tidak saja terdapat di dalam taritarian Papua, Sunda, dan Aceh. Akan tetapi, juga banyak ditemukan dalam tari-tarian di belahan dunia lainnya, terutama di Asia, lebih khusus lagi di Asia Tenggara. Berbeda dengan ballet yang gerakan (kakinya) lebih terkesan mengambang dan senantiasa meringankan badannya seperti ingin terbang. Tumpuan badan penarinya berada pada ujung jari-jari kaki. Tarian Indonesia, berat badan itu justru bertumpu di telapak kaki, kiri atau kanan, atau kedua-duanya.

Dalam setiap gerakan tidak ada kebakuan karena gerak-geraknya muncul dari spontanitas dan kelincahan ataupun keaktratifan dari penari ronggeng (penari perempuan) atau pamogoran (penari lakilaki). Berkaitan dengan pekerjaan instalasi, di mana AR Pasua PA merupakan komponen integral dari karya seni akhir dan bukan hanya tempat di mana karya seni berada baik di Papua, Sunda, maupun Aceh. Dalam hal ini peneliti dan mitra penelitian benar-benar bekerja dengan ruang sebagai komponen karya selama fase pengembangan AR Pasua PA. Jika memungkinkan, pekerjaan dilakukan di lokasi Papua, Sunda, dan Aceh; jika tidak, peneliti sebanyak mungkin melakukan pekerjaan dalam ruang sementara, seperti laboratorium atau studio. Karya seni AR Pasua PA mungkin tidak hanya dipentaskan di proscenium atau dipamerkan di galeri, melainkan dapat dipasang di situs tertentu. Jika pekerjaan itu spesifik untuk situs, situs itu sendiri adalah komponen yang termasuk dalam proses pengembangan karya seni.

\section{PENUTUP}

Literasi teknologi dengan metode eksplorasi dengan mencoba penggunaan teknologi augmented reality (AR) ini sebagai salah satu metode pembelajaran di PT Seni sebagai variasi media pembelajaran dan cara penyampaian materi perkuliahan, agar mahasiswa tidak mengalami kejenuhan dalam proses belajar mengajar (PBM). Proses pembelajaran melalui media visual ada yang berupa gambar diam dan bergerak seperti animasi gerak tari, film strip (film rangkai), slides (film bingkai, foto, gambar atau lukisan dan cetakan, gambar atau simbol yang bergerak, seperti film bisu dan kartun. Literasi tubuh virtual dengan model penerapan teknologi Augmented Reality (AR) PASUA (Papua Sunda Aceh) Performance Arts yang disingkat AR PASUA PA. Literasi teknologi sebagai pembelajaran dengan AR sebagai model pengembangan pembelajaran 4.0 yang terpadu berbasis seni, budaya, teknologi digital juga dapat diterapkan di Perguruan Tinggi Seni di Indonesia, khususnya Institut Seni Budaya Indonesia (ISBI) Bandung, ISBI Papua, dan ISBI Aceh. Perkembangan teknologi seni pertunjukan 
selanjutnya diciptakan sebagai upaya untuk menambah nilai kegunaan bagi peradaban masyarakat modern, khususnya untuk kepentingan pengembangan pembelajaran seni budaya era 4.0.

Literasi teknologi dengan aplikasi augmented reality (AR) diterapkan dalam seni pertunjukan memberikan dampak potensial pada masa depan literasi bahasa tubuh dalam seni pertunjukan dan pendidikan seni pada peradaban masyarakat modern. Literasi teknologi ini, dalam penggunaan augmented reality menjadi nafas baru dalam pemanfaatan teknologi sebagai ruang eksperimental dalam proses penciptaan karya baru seni pertunjukan khususnya di Papua-Sunda-Aceh. Kreativitas dalam pembuatan AR PASUA PA merupakan proses kreatif seni pertunjukan dengan mendigitalisasikan karya seni dari tiga tarian tersebut.

Dengan demikian, memelihara tradisi bukanlah sekedar memelihara bentuk tetapi lebih pada jiwa dan semangat atau nilai-nilai. Oleh karena itu, dengan lebih leluasa dapat melakukan interpretasi dan menciptakan kembali, sekaligus kita juga akan mewarisi sikap kreatif dan imajinasi yang subur sebagaimana dimiliki nenek moyang kita yang telah berhasil menciptakan karya-karya besar di masa lampau. Dengan demikian, kita akan selalu dapat menyelaraskan semangat kesenian tradisi dengan perkembangan kehidupan masyarakat sesuai dengan peradaban masyarakat modern dengan tidak meninggalkan akar dari peradaban masyarakat sebelumnya.
Dalam dunia virtual yang sudah memasuki realita di mana sebagian besar pikiran dan waktu menjadi terserap ke dalam dunia virtual, bentuk seni seperti inilah yang dapat meninggalkan kesan lebih lama dibandingkan ketika jika mengapresiasi suatu pertunjukan baik secara pertunjukan langsung maupun jika melihat lukisan atau patung di museum. Dan dalam dunia di mana kehidupan seolah telah berpindah secara signifikan ke dalam realm virtual, menerima keberadaan dari ilusi realita yang disuguhi jenis seni seperti inilah yang justru berkesan, lebih dipahami, dan bisa tetap exist sebagai lebih daripada sekadar pameran seni 'asal lewat' saja. Kehadiran virtual reality ini menjadi wujud nyata ketahanan seni di masa digital bahwa seni mampu progresif dalam merespon zaman - dan menggugah pikiran dan perasaan melalui realita yang diciptakannya sendiri.

\section{Ucapan Terima Kasih}

Penulis menyampaikan ucapan terimakasih kepada RistekBRIN yang telah memberi bantuan dana Hibah Penelitian Penugasan Konsorsium Riset Perguruan Tinggi (KRUPT) Bidang Seni Pertunjukan tahun 2019-2021 dan PT. Assembrl Teknologi Indonesia, BPNB Papua sebagai Mitra Penelitian serta Perguruan Tinggi Seni anggota konsorsium yaitu ISBI Bandung, ISBI Aceh dan ISBI Tanah Papua. 


\section{Daftar Pustaka}

Beardsley, Monroe C. 1958. Aesthetics Problems in the Philosophy of Criticism. Swarthmore College. Harcourt, Brace and Company New York.

Chris Jenks. 2017. Culture Studi Kebudayaan. Yogjakarta: Pustaka Pelajar.

Edi Sedyawati. 1999. Seni Pertunjukan Indonesia dan Pariwisata. Bandung: Masyarakat Seni Pertunjukan Indonesia.

Eko Supriyanto. 2018. Ikat Kait Impulsif Sarira. Yogjakarta: Garudhawaca.

Kaye, Nick, 1994. Postmodernism and Performance, New York : Macmillan Education.

LIPI.1984. Kapita Selekta Manifestasi Budaya Indonesia. Bandung: Badan Penelitian dan Pengembangan Departemen Luar Negeri bekerja sama dengan Penerbit Alumni.

Mohd Anis MD Nor. 1986 ."Randai Dance of Minangkabau Sumatera with Labanotation Scores". Jurnal Tirai Panggung. Kuala Lumpur: Universiti Malaya.

Mohamad Yusuf Wiradiredja. 2015. “Proses Kreatif dalam Penciptaan Lagu Bersumber Visi Misi Kabupaten" dalam Jurnal Ilmiah Seni dan Budaya Panggung Vol 25 No 1 Edisi Maret. Bandung: LPPM ISBI Bandung.

Oong Maryono. 1998. Pencak Silat Merentang Waktu. Yogyakarta: Galang press.

Peake, Ian D., Jan Olaf Blech, Shyam Nath, Jacob Jacky Aharon, Argyll McGhie, RMIT University, 16 November 2017.

Sal Murgiyanto. 2002. Kritik Tari: Bekal dan kemampuan Dasar. Jakarta: Ford Foundation dan MSPI.

1991. “Minangkabau Dance Redefined: 1968 - 1971", dalam Disertasi "Moving Between Unity and Diversity, Four Indonesian Choreographers". New York: New York University.

Sri Rustiyanti, Wanda Listiani. 2017. “Visualisasi Tando Tabalah Penari Tunggal dalam Photomotion
Pertunjukan Rampak Kelompok Tari Minang" dalam Jurnal Seni Budaya Mudra Vol 32 No 2 Edisi Mei. Bali: LP2MPP ISI Denpasar.

Sri Rustiyanti. 2011. "Konsep estetik Tari Minang dari Tradisional ke Kontemporer" dalam Jurnal Ilmiah Seni dan Budaya Panggung Vol 21 No 3 Edisi Juli-September. Bandung: LPPM ISBI Bandung.

Sri Rustiyanti. 2019. “Metode 'TaTuPa' Tabuh Tubuh Padusi sebagai Musik Internal Visualisasi Koreografi NeoRandai" dalam Journal of Performing Arts Resital Vol 20 No 3 Edisi Desember. Jogyakarta: Fakultas Seni Pertunjukan.

Yasraf A. Piliang. 2018. Medan Kreativitas: Memahami Dunia Gagasan. Yogjakarta: Cantrik Pustaka.

Yasraf A. Piliang. 1998. “Realitas Baru Estetik Prespektif Seni dan Disain menuju abad ke 21" dalam Jurnal Seni No. VI/01 edisi Mei 1998.

\section{Virtual}

http://www.unesco.org/new/en/education/ themes/education-building-blocks/ literacy/

https://www.dkampus.com

https://www.dosenpendidikan.co.id/literasiadalah/

https://etd.unsyiah.ac.id/baca/index. php?id=25474\&page $=62$

1. Antropologi Budaya, Fakultas Budaya dan Media ISBI Bandung

2. Desain Komunikasi Visual, Fakultas Seni Rupa dan Desain ISBI Bandung

3. Seni Teater, Fakultas Senin pertunjukan ISBI Aceh

4. Seni Tari, Fakultas Seni Pertunjukan ISBI Papua 